\title{
SUCCESS PATTERNS FOR THE DIGITAL TRANSFORMATION OF B2B COMMERCE
}

\author{
Matthias Lederer and Jan-Gerd Bruns \\ ISM International School of Management, D-Karlstraße 35, 80333 Munich, Germany
}

\begin{abstract}
Various companies in different industries face a variety of new technological opportunities, often referred as digital transformation. This research collects and classifies successful cases for digital transformation in the business-to-business (B2B) commerce. The initial qualitative analysis of 80 cases results in the derivation of eight potential patterns. For example, it can be concluded from the dataset that B2B companies are enriching their web shops with personal service, data-driven features or individual media. Some companies transform their B2B product portfolio to connected smart solutions and newly also sell to end-consumers. Moreover, it seems that offline and online services as well as sales and communication channels are combined in innovative ways to be prepared for a digital future.
\end{abstract}

\section{KEYWORDS}

Digital Transformation, B2B Transactions, E-Business Models, Best Practices

\section{MOTIVATION}

The economic potential of digitization in B2B (business-to-business) transactions is considered to be strong, but has not been completely analyzed in the scientific and practical discourses on digital transformation (Pagani \& Pardo, 2017; Marketing Leadership Council, 2015). For example, in public discourses, the various applications of the "GAFA" players (Google/Alphabet, Amazon, Facebook, Apple) are dominant. Many of the digital innovations focus on marketing-oriented issues (e.g., individualized advertising on Facebook, increasing customer experience with AmazonWebServices, etc.). Available applications are widely used to enhance B2C (business-to-consumer) commerce (e.g., Amazon Echo and Apple as a platform for innovative sales applications, Google as an advertising partner in the customer journey, etc.) (Horovitz, 2017).

Nonetheless, the potential for digital solutions in B2B commerce, understood as the sale of goods and services to professional customers using the Internet, is tremendous (Lindh \& Nordman, 2018). Depending on the industry, the degree of digitization in B2B is even less than 40 percent (Bughin et al., 2017). The overall digital maturity of $\mathrm{B} 2 \mathrm{~B}$ providers is increasing, but is on average lower than at $\mathrm{B} 2 \mathrm{C}$ companies (Catlin et al., 2016). So far, the major focus of B2B projects in digital transformation, understood as the application of digital technologies to improve design parameters of a company, was on internal processes like production (e.g., smart factory), back-office workflows (e.g., automation of services) and resource planning (e.g., predictive technologies) (Statista, 2017; Lingqvist, 2015).

According to statistics, B2B commerce is growing steadily worldwide with a growth rate of about five to ten percent (global gross merchandise volume in 2013 was 5.826 and 7.661 billion U.S. dollars in 2017) (Statista, 2017; Lingqvist, 2015). Traditional small and medium-sized (SME) B2B companies seem still to be a long way from a comprehensive digitalization of their transactions or from disruptive innovations in e-commerce. Nevertheless, they need to adapt to the dynamic conditions of concentrated online and digital markets in order not to risk their competitive position (Lässig, 2016). At the same time, they will not be able to prevail against new digital global players (e.g. Alibaba).

This work-in-progress collects cases, in which B2B companies succeeded in implementing new digital techniques, processes, services and products in order to increase their economic success. The question of how success of digital transformation projects can be measured and compared, is currently the subject of various studies. Typically, they use or combine insights from existing research fields such as process management, innovation management or accounting, or from the functions concerned by the transformation (such as 
marketing, purchasing, sales, etc.). Comparing recent surveys of companies and theoretical work, the turnover of new/additional products and services, the extent of optimized processes as well as classic productivity and profitability figures are often mentioned. It is noteworthy that more frequently the extraction and analysis of data (business analytics) is seen as success parameter (e.g. survey by IDC, 2018).

In this article, digital transformation is understood as a comprehensive and sustainable change process of transactions or business models that is enabled by newly available digital technologies (Lankshear \& Knobel, 2008; Heinze et al., 2018). Collected cases are examined according to common significances. Significant patterns to be identified are understood as possibly imitative behaviors of companies that can increase the respective business success (Streuer et al., 2016). As a summary, the aim of this research is to answer the following question:

Which patterns can be drew from B2B commerce cases, which successfully carried out a digital transformation?

\section{METHODOLOGY}

The methodology of this research follows a multi-case design (Herriott, 1983) combined with an integrative review (Kornmeier, 2007). For this documentation, the approach should be documented in four steps:

- Search and selection: In order to ensure a scientific basis and to not use any self-marketing or consulting publications, only documents from scientific databases (e.g., EBSCO) have been used to identify cases. The two central limiting parameters ("digital transformation" and "B2B" transactions; including synonyms) designed the search string.

After reviewing more than 3,000 documented cases, only those were considered that fulfill an explicit proof of business success (for example with key figures) as well as supplementary quality standards (for example completeness, correctness, still existing business models). Since many forms of success are discussed (see above), one concrete proof is sufficient in the classical views on successful company developments (resource, capability, leadership and process) (Muller et al., 2005).

- Coding: For the 80 cases so far, a total of 26 attributes for each was coded to determine the transformation approaches. In addition to metadata (e.g., name, company size, industry, sales areas) and the actual business model/model change (parts of the Business Model Canvas), the orientation within recognized classifications (e.g., the St. Gallen business model navigator) and some other attributes (e.g., success measures) were extracted from the cases.

- Analysis: So far, a qualitative analysis was carried out by deducing general theses in the dataset (Lee, 2002). The qualitative content analysis overall followed the recommended approach of (Mayring, 2014). Based on the research question, the deductively generated criteria were semantically analyzed with their relative distribution. Based on the formal analysis, suitable cases were structured inductively. Both the contained criteria as well as the common content of the cases lead to explicitly formulated patters as interpreted summary of transformation approaches.

- Documentation: Patterns identified so far have been described and interpreted in a standard template for Best Practices documentation (including for example key changes, risks, opportunities, performance measures and sample companies). The specified number (n) of each pattern indicates in the following section how many of the 80 cases fall into the described type of digital transformation.

\section{PRELIMINARY RESULTS}

Based on the previous qualitative analysis, eight patterns in the digital transformation of B2B commerce could be identified. They will be shortly introduced using examples: 
- B2B companies conquer the B2C markets $(n=11)$ : Established B2B companies are increasingly acquiring private end-customers. Most of these companies come from the fast-moving consumer goods industry. By omitting wholesalers and retailers through digital channels, these companies realize lower prices and gain a better customer understanding.

For example, Flexfire LED, a manufacturer of indoor and outdoor lighting, nowadays generates $20 \%$ of sales in the end-consumer sector.

- Marketplaces organized by large-sized companies ( $n=8)$ : Four companies (Amazon Business, Alibaba, Klöckner and Mapudo) predominantly organize transactions on digital B2B marketplaces. It can be concluded from the dataset, that the creation and sustainable operation of such platforms with a critical mass goes hand in hand with large investments only large companies can afford.

- B2B companies transfer physical to digital goods $(n=9)$ : Many companies enrich their traditional product portfolio by connectivity und smartness. The actual added value is more perceived by its new digital possibilities.

Smart farming, as offered for example by Claas, means that farmers profit from agricultural management systems including integrated harvester and connected stock cabins.

- From online service to offline service or multi-channel offers $(n=19)$ : A lot of companies still rely on offline services (e.g. personal on-site advice) although they aim to reduce transaction cost. Personal support is needed to handle complex products or orders of considerable investment, but it is now often part of a cross-channel solutions.

For example, the tool manufacturer Hilti placed a new contact possibility for personal help (e.g. video chat) on its B2B online shop page. So called "Hilti Center" offer stationary help for online customers.

- Digital channels reduce transaction costs $(n=38)$ : The most frequent focus of B2B transactions of standard products is reducing transaction costs through digital channels (e.g. Electronic Data Interchange $[E D I])$. Tendencies can be observed, which go away from classical interface standardization (e.g. EDIFACT).

Hirschmann Automotive for example speeded up the order process by offering free digital samples. If engineers and developers are convinced, they have access to all internal planning processes (advanced interface) to optimize their own scheduling.

- Modern mass Customization $(n=8)$ : Especially manufacturers were successful in adapting products to the individual needs of customers at the price of mass production.

At Zeppelin Cat, excavators can be pre-configured and ordered including a real-time support by digital consultants. Goin, as another example, sells furniture for restaurants using an online configurator. It offers a 3D room planning showing the furnishing concept including service routes for the operating staff.

- Added value through experience selling $(n=23)$ : Some B2B providers offer their customers a new shopping experience. In addition to the pure sale, companies tend to new forms of product and service impressions with emotional attraction or technical richness.

The e-bikes manufacturer Riese \& Müller, for example, launched a dealer portal displaying about 1.2 million configuration options with real-time pricing. While increasing the orders, the number of support requests was reduced due to media items (e.g. video guidelines) available for all configurations.

- SMEs acquire new customers $(n=19)$ : It become clear that especially SMEs often take the chance of their flexibility to adapt to new market conditions and are thus able to gain new customers in existing segments.

Lex \& Hesse, a wholesaler of spare parts for buses and rail vehicles employing about 30 people, has for example been able to generate a $500 \%$ increase in turnover by the introduction of a new B2B shop. It focuses on very specific requirements such as automated transfer of orders. 


\section{CONCLUSION AND IMPLICATIONS}

The analysis shows that successful digital transformations in B2B commerce in principle follow generic patterns. They can serve as a set of templates for the creation of digital innovations especially in traditional companies. At the same time they can now be used to further investigate detailed obstacles and beneficial factors. The patterns derived can serve as a basis for discussions with researchers from multiple fields. The various identified example cases are suitable for concrete discourses with practitioners. Especially against the background that in the context of digital transformation, often only general trends, rough ideas and exaggerated scenarios are described (Mertens \& Barbian, 2016), an extended analysis of this dataset might give specific answers for the future of B2B transactions. Although some of the identified patterns are known in established literature, the dataset has the potential to provide answers and applicable solutions for the digital transformation of B2B commerce. The attributes documented for each successful case show specifics for the different types of transactions and business models (e.g., complex vs. standard products, focus on new vs. old customer groups, own vs. third-party development, etc.). In particular, the detailed analysis may provide new insights into the clever combination of sales media, which is occasionally discussed under the term omni-channel.

After this initial qualitative analysis, the authors extend the dataset in current research by adding further cases. The aim is to substantiate the patterns with quantitative proofs and further analyzes (exact dependencies of the attributes) early next year. In ongoing case studies, the authors are also about to examine the applicability of previously documented patterns in German SMEs.

\section{REFERENCES}

Bughin, J. et al, 2017. The digital reinvention, McKinsey Quarterly, Vol. 02/2017.

Catlin, T. et al, 2016. How B2B digital leaders drive five times more revenue growth than their peers. McKinsey, New York.

Heinze, A. et al, 2018. Knowledge exchange partnership leads to digital transformation at Hydro-X Water Treatment. Global Business and Organizational Excellence, Vol. 37, No. 4, pp. 6-13.

Herriott, R.E. and Firestone, W.A., 1983. Multisite Qualitative Policy Research: Optimizing Description and Generalizability. Educational Researcher Vol. 12, No. 2, pp. 14-19.

Horovitz, B., 2017. Impacting Consumers, Upending Retail: Why Amazon, Apple, Facebook and Google rule. Stores Magazine. Vol. 99, No. 8, pp. 38-40.

IDC 2018. Digital Transformation KPIs to Enable Systems of Accountability. IDC PlanScape, 09/2018.

Kornmeier, M., 2007. Wissenschaftstheorie und wissenschaftliches Arbeiten. Physica, Mannheim.

Lankshear, C. and Knobel, M., 2008. Digital literacies. Zirndorf: Peter Lang Publishing.

Lässig, R. et al, 2016. Die digitale Zukunft des B2B-Vertriebs. Google/Roland Berger, New York.

Lee, A. S., 2002. A Scientific Methodology for MIS Case Studies. In Myers, M. D. and Avison, D., 2002. Qualitative Research in Information Systems. SAGE, London.

Lindh, C. and Nordman, E., 2018. New Service Development and Digitalization: Synergies of Personal Interaction and IT Integration. Services Marketing Quarterly, Vol. 39, No. 2, pp. 108-123.

Lingqvist, O. et al, 2015. Do you really understand how your business customers buy?, McKinsey Quarterly, Vol. 05/2015.

Marketing Leadership Council, 2015. The digital Evolution in B2B Marketing - Research Studies. The Corporate Executive Board Company, Washington.

Mayring, P., 2014. Qualitative content analysis. Belt, Klagenfurt.

Mertens, P. and Barbian, D., 2016. Digitalisierung und Industrie 4.0. Friedrich-Alexander-University, Nuremberg.

Muller, A. et al. 2005. Metrics for innovation: Guidelines for developing a customized suite of innovation metrics. Strategy \& Leadership, Vol. 33, No. 1, pp. 37-45.

Pagani, M. and Pardo, C., 2017. The impact of digital technology on relationships in a business network. Industrial Marketing Management. Vol. 67, No. 11, pp. 185-192.

Statista, 2017. B2B e-Commerce 2017 - Digital Market Outlook. Statista Trend Report, Hamburg.

Streuer, M. et al, 2016. Profit Driving Patterns for Digital Business Models. Proceedings of International Society for Professional Innovation Management Conference. Worsley, pp. 1-14. 